Rev. Biol. Neotrop. 4(1): 58-63. 2007

\title{
Uebra de dormência de sementes de Chamaecrista fleXuosa (L.) Greene Leguminosae visando a restauração ecológica do Cerrado
}

\author{
Fernando Campanhã Bechara \\ Universidade Tecnológica Federal do Paraná (UTFPR). Coordenação de Engenharia Florestal \\ do Paraná, Estrado para Boa Esperança, km 04, caixa postal157, CEP 85560-000, Dois \\ vizinhos-PRSBRASIL; E-mail: bechara@utfpr.edu.br
}

\author{
Gelson Dias Fernandes \\ Universidade de São Paulo, ESALQ, Piracicaba, São Paulo, Brasil
}

\author{
Raquel Lima da Silveira \\ Casa da Floresta Assessoria Ambiental, Piracicaba, São Paulo, Brasil
}

\begin{abstract}
Resumo: O Cerrado é considerado um bioma de absoluta importância para a conservação por sua alta riqueza biológica e pela alta pressão antrópica a que vem sendo submetido. Restaurar representa um desafio no sentido de iniciar um processo de sucessão o mais semelhantemente possível com os processos naturais, incluindo todas as formas de vida. Chamaecrista flexuosa (L.) Greene (canela-de-ema), Leguminosae-Caesalpinioideae, é um subarbusto ruderal trianual, de rápido crescimento, com frutificação precoce e abundante. A introdução de $C$. flexuosa em núcleos adensados possui alto potencial de recuperação de solos e atração de animais polinizadores. Plantas herbáceo-arbustivas, componentes das primeiras fases seriais, são importantes no combate de gramíneas exóticas invasoras e na adequação ambiental para a chegada de espécies mais exigentes. Visando a quebra de dormência das sementes de $C$. flexuosa foi efetuado um teste de emergência de plântulas em delineamento inteiramente aleatorizado, com oito repetições de 25 sementes por tratamento. A dormência das sementes foi quebrada através de imersão em água a $80^{\circ} \mathrm{C}$ por 5 segundos, o que resultou em $73,5 \%$ de emergência.
\end{abstract}

Palavras-chave: Cerrado, espécie arbustiva, Leguminosae, nucleação, teste de germinação.

Abstract: Brazilian Cerrado is considered a biome of high importance for conservation due to its high biological diversity and the high anthropic pressure it has been submitted to. The recuperation of this biome represents a challenge to initiate a process of succession as similar as possible to the natural processes, including all forms of life. Chamaecrista flexuosa (L.) Greene (canela-de-ema), Leguminosae-Caesalpinioideae, a triannual ruderal subshrub, presents fast growth and precocious and abundant fruition. The introduction of $C$. flexuosa in dense nuclei possesses high potential of soil recovery and attraction of pollinators. Herbaceous-shrubby plants, components of the first seral phases, are important to combat exotic grass invaders and to turn the environment more suitable for the arrival of more demanding species. To break $C$. flexuosa seed dormancy, an entirely randomized test of seedling emergence was carried out, with eight repetitions and 25 seeds per treatment. Seed dormancy was broken by immersion in water at $80^{\circ} \mathrm{C}$ for 5 seconds, resulting in $73.5 \%$ of emergence.

KeY woRDs: Cerrado, shrubby species, Leguminosae, nucleation, germination test.

\section{INTRODUÇÃo}

$\bigcirc$ Cerrado é considerado um hotspot, isto é, bioma de absoluta importância para a conservação por sua alta riqueza biológica e pela alta pressão antrópica a que vem sendo 
submetido (Myers et al., 2000). No estado de São Paulo, as formações de Cerrado são descontínuas, ocorrendo como encraves em meio à Floresta Estacional predominante. Estima-se uma perda de $88,5 \%$ da área original do Cerrado paulista, havendo apenas 211.925 ha remanescentes (Kronka, 2005).

Restituir ecossistemas representa um desafio no sentido de iniciar um processo de sucessão que seja o mais semelhante possível aos processos naturais, formando comunidades com biodiversidade que tendam a uma rápida estabilização, incluindo todas as formas de vida (Reis et al., 2003; Reis \& Wiesbauer, 2006).

Tradicionalmente, os modelos de recuperação ambiental têm se baseado em tecnologias de plantio de espécies exclusivamente arbóreas. As plantações de árvores nativas desenvolvem-se em altura e área basal, com alta produção de madeira, mas o estrato regenerativo fica dominado por gramíneas exóticas invasoras (Souza \& Batista, 2004) que estagnam a sucessão. Assim, tais plantações "saltam" as primeiras fases seriais, caracterizadas pela colonização por organismos de pequeno porte, espécies herbáceo-arbustivas tais como ervas, lianas e arbustos (Bechara, 2006). A importância de trabalhar com espécies herbáceo-arbustivas em projetos de restauração ecológica (Bechara, 2006) reside no fato de que essas formas de vida atraem precocemente uma série de animais polinizadores e consumidores, além de recobrir o solo com rapidez, facilitando a chegada de espécies mais exigentes (Connel \& Slatyer, 1977; Klein, 1979).

As espécies de Chamaecrista (Leguminosae-Caesalpinioideae), são espécies herbáceoarbustivas ruderais de rápido crescimento e frutificação precoce e abundante. Típicas de ecossistemas de vegetação aberta recentemente antropizadas, distribuem-se espacialmente em forma de núcleos densos que facilitam o estabelecimento de outras espécies vegetais (Martinez, 2003; Yarranton \& Morrison, 1974).

Chamaecrista flexuosa (L.) Greene é um sub-arbusto trianual que possui distribuição ampla e ocorre em quase todo o Brasil. É comum em vegetações pioneiras e beiras de estrada em fitofisionomias de Cerrado. Apre- senta grande quantidade de flores amarelas e nectários extraflorais que atraem uma série de animais polinizadores, tais como himenópteros e coleópteros (Aguiar, 2003; Camargo \& Miotto, 2004; Ruhren, 2003). Apresenta dormência tegumentar em decorrência de sua impermeabilidade à água, característica inerente à maioria das espécies leguminosas (Bewley \& Black, 1994). Entretanto, ao contrário da maior parte das espécies de Caesalpinoideae, C. flexuosa apresenta nódulos de bactérias nitrificantes, o que promove a nitrogenação e a recuperação do solo (Naisbitt et al., 1992; Sprent, 2001).

A germinação é um fenômeno biológico que tem início com a absorção de água pela semente e termina com a elongação do eixo embrionário, geralmente a radícula, com o conseqüente rompimento do tegumento da semente (Labouriau, 1983; Bewley \& Black, 1994). Em condições naturais, os fatores luz e temperatura são decisivos no padrão de dormência de sementes e podem operar em sua superação ou indução (Bewley \& Black, 1994).

Há uma lacuna de conhecimento referente a estudos sobre germinação de espécies Chamaecrista e de outras plantas herbáceoarbustivas ruderais de Cerrado, estando as pesquisas básicas e aplicadas de espécies nativas concentradas nas formas de vida arbóreas (Aguiar et al. 1993; Higa \& Silva, 2006). Através da quebra de dormência de suas sementes, pretende-se potencializar a introdução de C. flexuosa em projetos de restauração ecológica que visem empregar modelo de restituição considerando a sucessão secundária inicial em Cerrado.

\section{Material e métodos}

A área de coleta das sementes para este estudo está localizada na Fazenda Cara Preta, município de Santa Rita do Passa Quatro, entre as coordenadas centrais $21^{\circ} 37^{\prime} 19^{\prime \prime} \mathrm{S}$ e 47 $33^{\prime} 08^{\prime \prime} \mathrm{W}$, nordeste do estado de São Paulo. A região apresenta altitude de $588 \mathrm{~m}$, latossolo vermelho-amarelo de textura arenosa fina, déficit hídrico de abril a setembro, precipitação média anual de $1.478 \mathrm{~mm}$ e temperatura média de $21^{\circ} \mathrm{C}$ (ESALQ, 2005). As sementes de $C$. 
flexuosa foram coletadas em área abandonada, um ano após o corte de plantação comercial de Eucalyptus sp., quando a espécie formou núcleos densos em uma matriz de gramíneas exóticas invasoras (Melinis minutiflora P. Beauv., Brachiaria sp., Rhynchelytrum repens (Willd.) C. E. Hubb, Eleusine sp. e Ichnanthus sp.).

Inicialmente, o número de sementes de C. flexuosa foi estimado por quilograma através da amostragem de dez repetições de $2 \mathrm{~g}$ de sementes, pesadas em balança digital. Então, as sementes foram submetidas aos seguintes tratamentos de imersão em água a diferentes tempos e temperaturas: tratamento $\mathrm{T}_{1}$ - testemunha; tratamento $\mathrm{T}_{2}$ - imersão em água a $80^{\circ} \mathrm{C}$ por 5 segundos; tratamento $\mathrm{T}_{3}$ - imersão em água a $80^{\circ} \mathrm{C}$ por 10 segundos; tratamento $\mathrm{T}_{4}$ - imersão em água a $80^{\circ} \mathrm{C}$ por 15 segundos; tratamento $\mathrm{T}_{5}$ - imersão em água à temperatura ambiente por 1.800 segundos; tratamento $\mathrm{T}_{6}$ - imersão em água à temperatura ambiente por 3.600 segundos; e tratamento $\mathrm{T}_{7}$ - imersão em água à temperatura ambiente por 7.200 segundos. Depois de submetidas a esses tratamentos pré-germinativos, as sementes foram distribuídas em caixas de germinação, com exceção do tratamento testemunha onde elas foram diretamente colocadas nas caixas, sem imersão em água.

Foi utilizado delineamento inteiramente aleatorizado, com cada tratamento sendo composto por oito repetições de 25 sementes, totalizando 1.400 sementes. Cada repetição foi disposta em uma caixa de germinação com 150 $\mathrm{ml}$ de vermiculita e $60 \mathrm{ml}$ de água (mantendose o substrato úmido). As unidades amostrais foram colocadas em estufa a $25^{\circ} \mathrm{C} / 16$ horas e $30^{\circ} \mathrm{C} / 8$ horas por 24 dias. Foram consideradas plântulas emersas aquelas que emitiram o par de folhas cotiledonares.

Foi realizada uma análise exploratória para verificação da normalidade dos dados por meio do teste de Shapiro-Wilk. Os tratamentos foram comparados estatisticamente através de análise de variância (teste F de Snedecor) e teste de separação de médias (Tukey), com o auxílio do pacote estatístico SAS. Também foi calculado o coeficiente de variação experimental $(\mathrm{CVE} \%)$, sendo CVE\% = (quadrado médio do resíduo ${ }^{1 / 2} /$ média experimental) $\mathrm{x} 100$.

\section{Resultados}

Foi estimado que Chamaecrista flexuosa possui aproximadamente 34.850 sementes por quilograma. No teste de emergência, os dados obtidos apresentaram normalidade, validando a análise de variância. O coeficiente de variação experimental foi de $16,48 \%$, indicando bom controle do erro experimental e boa precisão dos dados.

$\mathrm{O}$ tratamento pré-germinativo $\mathrm{T}_{3}$ - imersão em água, a $80^{\circ} \mathrm{C}$, durante $10 \mathrm{seg}$ - foi o que apresentou maior velocidade e maior porcentagem média de emergência de plântulas (73,5\%), sendo o mais indicado, entre os testados, para a quebra de dormência de sementes de C. flexuosa. Os tratamentos $\mathrm{T}_{3^{\prime}} \mathrm{T}_{7}$ - imersão em água, temperatura ambiente, durante 7.200 seg e $\mathrm{T}_{4}$ - imersão em água, a $80^{\circ} \mathrm{C}$, durante 15 seg, diferiram estatisticamente do tratamento testemunha, com 95\% de probabilidade (Tabela 1), corroborando a hipótese de que as sementes de $C$. flexuosa apresentam dormência.

Para todos os tratamentos, ocorreu um rápido pico de plântulas emersas logo aos 17 dias. Ao final de 24 dias já houve uma tendência à estabilização da curva de emergência (Figura 1).

\section{Discussão}

A dormência de sementes se constitui no fracasso de uma semente viável em completar a germinação sob condições favoráveis (Bewley, 1997). Em temperaturas constantes, as sementes tendem a permanecer dormentes (Bewley \& Black, 1994; Hilhorst, 1995).

Nas leguminosas, a dormência é originada por um bloqueio físico representado pelo tegumento resistente e impermeável que, ao impedir o trânsito de água e as trocas gasosas, não possibilita a embebição da semente e a oxigenação do embrião, o qual, por isso, permanece latente. Tais sementes, denominadas duras, alcançam grande longevidade e todo procedimento que rompa seu tegumento possibilita sua germinação e a emergência de plântulas, geralmente vigorosas (Grus, 1990). Esses procedimentos podem incluir escarificação mecânica (superfícies abrasivas ou lâmi- 


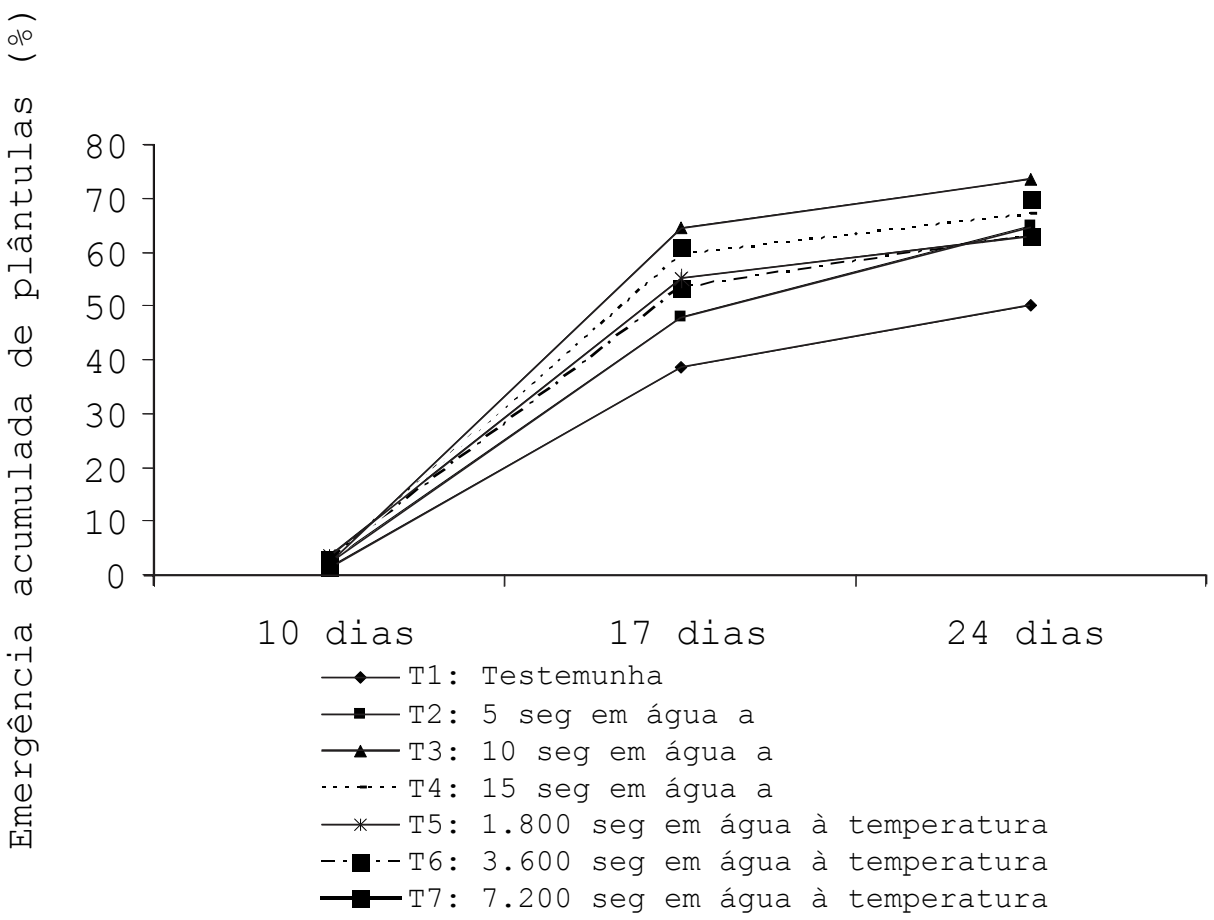

Figura 1. Porcentagem de emergência de plântulas de Chamaecrista flexuosa procedentes de Cerrado, município de Santa Rita do Passa Quatro, SP, sob diferentes tratamentos pré-germinativos.

Tabela 1 - Porcentagem média de emergência de plântulas de Chamaecrista flexuosa ao final de 24 dias, sob diferentes tratamentos pré-germinativos. Sementes procedentes de Cerrado, município de Santa Rita do Passa Quatro, SP.

Tratamento Emergência de plântulas (\%)

$\mathrm{T}_{3}$ : imersão em água a $80^{\circ} \mathrm{C}$ por $10 \mathrm{seg}$

$73,5 \mathrm{~A}$

$\mathrm{T}_{7}$ : imersão em água à temperatura ambiente por $7.200 \mathrm{seg}$

$70,0 \mathrm{~A}$

$\mathrm{T}_{4}$ : imersão em água a $80^{\circ} \mathrm{C}$ por $15 \mathrm{seg}$

$\mathrm{T}_{2}$ : imersão em água a $80^{\circ} \mathrm{C}$ por $5 \mathrm{seg}$

$65,0 A B$

$\mathrm{T}_{5}$ : imersão em água à temperatura ambiente por $1.800 \mathrm{seg}$

$63,0 \mathrm{AB}$

$\mathrm{T}_{6}$ : imersão em água à temperatura ambiente por $3.600 \mathrm{seg}$

$63,0 \mathrm{AB}$

$\mathrm{T}_{1}$ : testemunha

$50,0 \mathrm{~B}$

Médias seguidas pelas mesmas letras não diferem entre si pelo teste de Tukey no nível de 5\% de significância.

nas), escarificação química (uso de ácidos ou bases) ou imersão em água quente (Toledo \& Marcos Filho, 1977). Porém, os dois primeiros procedimentos são, em geral, mais onerosos e de maior periculosidade (Popinigis, 1977).

Devido ao fato da prolongação da imersão de 10 para 15 segundos, a $80^{\circ} \mathrm{C}$, ter redu- zido a porcentagem de emergência de plântulas de C. flexuosa, seria apropriado submeter as suas sementes aos tempos intermediários. Da mesma forma, em ambas as temperaturas empregadas ocorreu um maior percentual de emergência de plântulas, sendo interessante a verificação de temperaturas intermediárias 
para atingir o choque térmico ideal. Tais investigações poderiam otimizar a germinação e, ao mesmo tempo, garantir a conservação das propriedades fisiológicas das sementes e do potencial de crescimento das plântulas. Adicionalmente, pode ser interessante o uso de inoculação de rizóbio em mudas de Chamaecrista spp. para uso em larga escala (Faria et al., 2003).

A produção de sementes e plântulas é um elo vital para o manejo e a restauração de áreas degradadas (Pinã-Rodrigues \& Piratelli, 1993; Reis \& Wiesbauer, 2006). Pelos testes realizados no presente trabalho, os resultados demonstram que a utilização de sementes de $C$. flexuosa apresenta elevado potencial para fins de restauração de Cerrados, seja via semeadura direta no solo ou através da produção de mudas. Para aplicação dessas técnicas, recomendamos o choque térmico para quebra da dormência tegumentar através da imersão das sementes em água a $80^{\circ} \mathrm{C}$ por 10 segundos.

Chamaechrista flexuosa é uma espécie rústica que forma densos núcleos trianuais e apresenta dominância serial logo após a perturbação de áreas naturais. Provavelmente, isso decorre de seu escape a predação (frutificação abundante), a herbivoria e a danos físicos ou por ser uma competidora superior pela presença de nodulação de raízes. Após sua senescência, os núcleos de C. flexuosa abrem espaço para o possível recrutamento de outras espécies mais exigentes (Connel \& Lowman, 1989).

Para a seleção de espécies a serem introduzidas em atividades restauradoras é imprescindível a observação da regeneração natural de conglomerados monoespecíficos (núcleos densos) de vegetação herbáceo-arbustiva em áreas recentemente abandonadas e próximas. As plantas efêmeras, como C. flexuosa, são essenciais em programas de restauração ecológica, posto que compõem as primeiras fases seriais, importantes no combate de gramíneas exóticas invasoras (Espindola et al., 2005) e na adequação ambiental para a chegada de espécies mais exigentes.

\section{Agradecimentos}

Os autores agradecem aos professores Ademir Reis (UFSC), Paulo Kageyama (ESALQ-USP), Lorrayne Bosquetti (UFG), ao Biólogo Eduardo Campos Filho e à Votorantim Celulose e Papel por ceder a fazenda e a infra-estrutura para este trabalho.

\section{ReferênCIAS}

Aguiar, C. M. L. 2003. Flower visits of Centris bees (Hymenoptera: Apidae) in an area of Caatinga (Bahia, Brazil). Stud. Neotrop. Fauna E. 38: 41-45.

Aguiar, I. B., F. C. M. Piña-Rodrigues \& M. B. Figliolia. 1993. Sementes florestais tropicais. ABRATES, Brasília, $350 \mathrm{p}$.

Bechara, F. C. 2006. Unidades demonstrativas de restauração ecológica através de técnicas nucleadoras: Floresta Estacional Semidecidual, Cerrado e Restinga. Tese de Doutorado. Universidade de São Paulo, Piracicaba.

Bewley, J. D. 1997. Seed germination and dormancy. The Plant Cell 9: 1055-1066.

Bewley, J. D. \& M. Black. 1994. Seeds: physiology of development and germination. Plenum Press, New York, 445 p.

Camargo, R. A. \& S. T. S. Miotto. 2004. O gênero Chamaecrista Moench (LeguminosaeCaesalpinioideae) no Rio Grande do Sul. Iheringia, Ser. Bot. 59: 131-148.

Connel, J. H. \& M. D. Lowman. 1989. Lowdiversity tropical rain forests: some possible mechanisms for their existence. Am. Nat. 134: 88-119.

Connel, J. H. \& R. O. Slatyer. 1977. Mechanisms of succession in natural communities and their role in community stability and organization. Am. Nat. 111: 11191144.

ESALQ. Escola Superior de Agricultura "Luiz de Queiroz". 2005. Núcleo de Monitoramento Agroclimático. Disponível em: <http:/ / www.lce.esalq.usp.br/nurma.html>. Acesso em: 5 nov. 2006.

Espindola, M. B., F. C. Bechara, M. S. Bazzo \& A. Reis. 2005. Recuperação ambiental e contaminação biológica: aspectos ecológicos e legais. Biotemas 18: 27-38. 
Faria, S. M, J. F. Moreira, F. C. Cordeiro \& R. L. Machado. 2003. Obtenção de estirpes de rizóbio para leguminosas florestais (aproximação 2004). Seropédica, Embrapa Agrobiologia. 10 p. (Embrapa Agrobiologia. Comunicado Técnico, 61).

Grus, V. M. 1990. Germinação de sementes de pau-ferro e cássia-javanesa submetidas a tratamentos para quebra de dormência. Rev. Brasil. Sem. 6: 29-35.

Higa, A. R. \& L. D. Silva. 2006. Pomar de sementes de espécies florestais nativas. FUPEF, Curitiba, 266 p.

Hilhorst, H. W. M. 1995. A critical update on seed dormancy. I. Primary dormancy. Seed Science Research 5: 61-73.

Klein, R. M. 1979. Ecologia da flora e vegetação do Vale do Itajaí. Sellowia 31: 109164.

Kronka F. J. N. 2005. Inventário florestal da vegetação natural do Estado de São Paulo. Instituto Florestal, São Paulo, 200 p.

Labouriau, L. G. 1983. A germinação de sementes. OEA, Washington, $174 \mathrm{p}$.

Martinez, M. L. 2003. Facilitation of seedling establishment by an endemic shrub in tropical coastal sand dunes. Plant Ecol. 168: 333-345.

Myers, N., R. A. Mittermeir, C. G. Mittermeir, G. A. B. Fonseca \& J. Kent. 2000. Biodiversity hotspots for conservation priorities. Nature 403: 853-858.

Naisbitt, I., E. K. James \& J. I. Sprent. 1992. The evolutionary significance of the legume genus Chamaecrista as determined by nodule structure. New Phytol. 122: 487-492.

Piña-Rodrigues, F. C. M. \& A. J. Piratelli, 1993. Aspectos ecológicos da produção de sementes, p. 47-81. In: I. B. Aguiar, F. C. M. Piña-Rodrigues \& M. B. Figliolia (Eds.), Sementes florestais tropicais. Brasília, ABRATES.

Popinigis, F. 1977. Fisiologia de sementes. AGIPLAN, Brasília, 289 p.

Reis, A. \& M. B. Wiesbauer. 2006. O uso de sementes na restauração ambiental, p. 83-92. In: A. R. Higa \& L. D. Silva (Eds.), Pomar de sementes de espécies florestais nativas. Curitiba, FUPEF.

Reis, A., F. C. Bechara, M. B. Espindola, N. K. Vieira \& L. L. Souza. 2003. Restauração de áreas degradadas: a nucleação como base para incrementar os processos sucessionais. Natureza \& Conservação 1: 28-36; 85-92.

Ruhren, S. 2003. Seed predators are undeterred by nectar-feeding ants on Chamaecrista nictitans (Caesalpineaceae). Plant Ecol. 166: 189-198.

Souza, F. M. \& J. L. F. Batista. 2004. Restoration of seasonal semideciduous Forest in Brazil: influence of age and restoration design on forest structure. Forest Ecol. Manag. 196: 275-285.

Sprent, J. I. 2001 Nodulation in Legumes. Royal Botanic Gardens, Cumbria, 146 p.

Toledo, F. F. D. \& J. Marcos Filho. 1977. Manual de sementes: tecnologia e produção. Editora Agronômica Ceres, São Paulo, $224 \mathrm{p}$.

Yarranton, G. A. \& R. G. Morrison. 1974. Spatial dynamics of a primary succession: nucleation. J. Ecol. 62: 417-428.

Recebido em 12.XII.2006 Aceito em 17.V.2007 